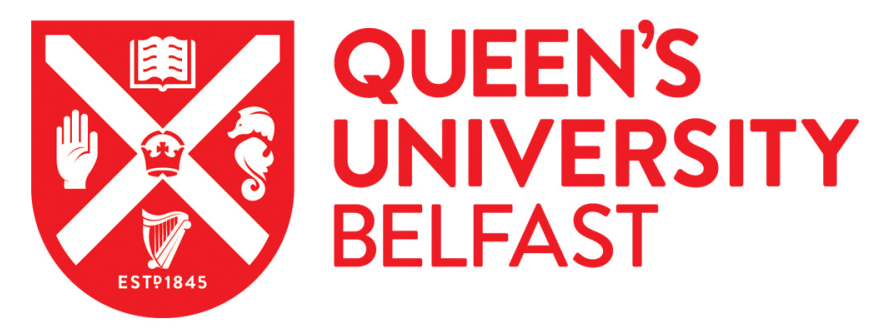

\title{
Demand Side Management of Public Clean Water Supply
}

Kernan, R., Liu, X., McLoone, S., \& Fox, B. (2015). Demand Side Management of Public Clean Water Supply. In 2015 50th International Universities Power Engineering Conference (UPEC): Proceedings Institute of Electrical and Electronics Engineers Inc.. https://doi.org/10.1109/UPEC.2015.7339923

Published in:

2015 50th International Universities Power Engineering Conference (UPEC): Proceedings

\section{Document Version:}

Peer reviewed version

\section{Queen's University Belfast - Research Portal:}

Link to publication record in Queen's University Belfast Research Portal

\section{Publisher rights}

(c) 2016 IEEE. Personal use of this material is permitted. Permission from IEEE must be obtained for all other uses, in any current or future media, including reprinting/republishing this material for advertising or promotional purposes, creating new collective works, for resale or redistribution to servers or lists, or reuse of any copyrighted component of this work in other works

\section{General rights}

Copyright for the publications made accessible via the Queen's University Belfast Research Portal is retained by the author(s) and / or other copyright owners and it is a condition of accessing these publications that users recognise and abide by the legal requirements associated with these rights.

Take down policy

The Research Portal is Queen's institutional repository that provides access to Queen's research output. Every effort has been made to ensure that content in the Research Portal does not infringe any person's rights, or applicable UK laws. If you discover content in the Research Portal that you believe breaches copyright or violates any law, please contact openaccess@qub.ac.uk. 


\section{Demand Side Management of Public Clean Water Supply}

\author{
Rónán Kernan \\ Queen's University Belfast \\ rkernan01@qub.ac.uk
}

\author{
Xueqin (Amy) Liu \\ Queen's University Belfast \\ x.liu@qub.ac.uk
}

\author{
Seán McLoone \\ Queen's University Belfast \\ s.mcloone@qub.ac.uk
}

\author{
Brendan Fox \\ Queen's University Belfast \\ b.fox@qub.ac.uk
}

This paper presents a study on the implementation of Demand Side Management (DSM) of electricity use at one clean water pumping station in Northern Ireland and the application of DSM to public water supply with the intention of maximising wind power production. This approach will lead to reductions in wind curtailment and improvements in system stability. It will also allow significant savings to be made on electricity costs for the water network.

Keywords: Demand Side Management, water, curtailment, variable generation, wind

\section{Nomenclature}

Variables:

$\begin{array}{ll}C_{i} & \text { Power price at } i, £ \\ C^{\text {max }} & \text { Maximum power price } £ \\ C^{\text {min }} & \text { Minimum power price } £ \\ D_{i} & \text { Water demand at } i, l / 15 \text { min } \\ i & \text { Time period } \\ P & \text { Pump flow rate } l / 15 \text { min } \\ R_{i} & \text { Reservoir level at time } i, l \\ R^{\text {max }} & \text { Maximum reservoir capacity, } l \\ R^{\text {min }} & \text { Minimum reservoir capacity, } l \\ R^{\text {start }} & \text { Reservoir level at start, } l \\ Q & \text { Threshold price for pumping, } £ \\ T^{\text {req }} & \text { Pumping requirement (periods) } \\ \sum T_{i}^{\text {run }} & \text { Sum of periods with pumping to } i\end{array}$

\section{INTRODUCTION}

The island of Ireland has an ambitious target of $40 \%$ renewable electricity generation by 2020. Most of this is anticipated to come from variable sources. $93 \%$ of Ireland's renewable generation is expected to come from wind power [1].

Ireland is a small and isolated electricity system, with a minor amount of interconnection compared to other European states [2]. The interconnection that does exist

is HVDC only, with no synchronised AC interconnection. This, along with the fact that wind generators are predominantly non-synchronous, has implications for system stability on a small isolated grid. As such, instantaneous system non-synchronous penetration (SNSP) is currently limited to $50 \%$ [1].

High demand rarely occurs at the same time as high wind generation. When load is low but wind generation is high, curtailment is often necessary to maintain the $50 \%$ SNSP limit. Curtailment tends to peak at night and reduces the economic case for wind power [3]. It is estimated that curtailment will increase to between $7 \%$ and $14 \%$ of all wind generation by 2020 - even with an increase of the SNSP limit to $60-75 \%$ [4].

DSM is necessary for economically feasible integration of high levels of variable generation. DSM allows some demand to be moved from peak times to periods of low demand and/or high wind, thus reducing the need for curtailment [3]. As wind power has negligible marginal costs, it tends to reduce the system marginal price (SMP) [5] and reduces the need for fossil-fired generation [6]. Ireland already has very high wind power penetration, with a corresponding effect on SMP [7] [8]. By using SMP as a signal influencing electricity consumption, consumers could reduce power costs - provided their tariff reflected price variability, and their consumption was flexible enough to make the most of price variation. This would reduce wind curtailment as periods of low SMP would often correlate with high wind scenarios.

Traditionally, the unit commitment problem has considered load as predictable but uncontrolled by the system operator, with generation being varied to ensure it is fulfilled. DSM allows more flexibility in the dispatch of generation by giving the system operator control of load. This is particularly advantageous with regard to wind as the lack of control over output can be compensated by an increased degree of control over load, allowing load to be dispatched to periods of high generation. This reduces overall system costs. DSM also reduces reserve requirements [9].

Traditional demand side resources such as domestic water heating and air conditioning systems or refrigeration need to be aggregated into large, controllable 'units' to have a significant effect on power system operation [10]. Keane et al [6] suggest consideration of aggregated demand side resources in the same category as generation. These 'units' would effectively act similarly to pumped storage systems: 'generating' (ie not consuming) during peak hours, and consuming off-peak. As peaking units, they would be very effective as they have no start-up 


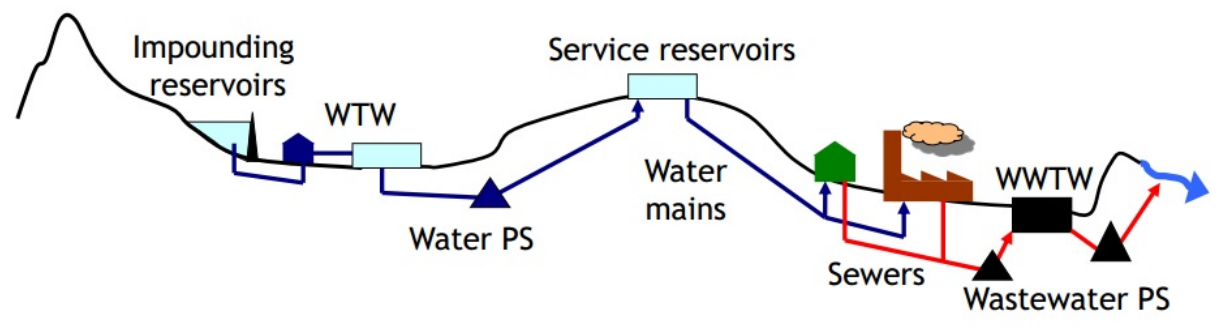

Figure 1: Water network schematic [11]

or fuel costs and no storage losses. They could also provide reserve capability.

It therefore follows that for large scale DSM systems to be effective, demand side units must be participants in the electricity market, receiving or paying a tariff based on SMP. DSM systems would reduce the requirement for expensive infrastructure upgrades such as energy storage by maximising the usage of existing assets.

Keane et al in [6] identified municipal water supply as a candidate for DSM. These represent a significant proportion of total electrical demand and have an inherent flexibility which leaves them well suited to DSM applications without affecting quality of supply.

Derceto [12], a New Zealand based company, produce a product, Aquadapt, which is currently the most advanced water pumping optimisation package available [13]. Aquadapt has been successfully used by a number of water utilities worldwide, resulting in electricity cost savings of up to $25 \%$ [14]. It has been implemented in a number of locations with a time of day tariff, and has also been utilised with a real time tariff in Washington, USA [12]. Both approaches led to large cost savings, with real-time pricing providing the largest saving.

While effective cost saving tools like Aquadapt already exist for water utilities, the impact of their implementation on the power system itself has not been considered.

The Irish electricity system serves as an excellent test system due to the fact that it is a small grid with minimal interconnection and very high wind power penetration [7]. Higher variation in system price would be expected on the Irish system compared to that of Washington due to high wind power penetration.

While the all-Ireland electricity system is considered as one market, there is only one significant interconnection between Northern Ireland (NI) and the Republic of Ireland (ROI). As such they are considered as separate but synchronised grids, with separate control centres for NI (System Operator for Northern Ireland - SONI) and ROI (Eirgrid). Public Water supply in NI is provided by NI Water (NIW), a public body, while in ROI responsibility for water is currently being unified under Irish Water [15]. This work considers only NI as data is more readily available from the longer established NIW.

NIW represents approximately $3 \%$ of NI electrical demand, of which half is from clean water pumping and treatment (Table 1). The water supply network has a similar demand curve to electrical power but reservoirs allow for storage, both in catchment areas and near centres of population. This storage is key to the potential flexibility of the system.

Water treatment works (WTW) are located at impounding reservoirs, and are used to ensure that water is safe for consumption. Treatment occurs at the WTW before an adjacent pumping station (PS) pumps the water to service reservoirs near the demand (Fig. 1). These store clean water until demanded by consumers. The PS is used to ensure sufficient water levels in the service reservoirs to maintain public supply. The flow rate of water through the PS is dependent on the flow through the WTW. It follows, therefore, that much of the electrical consumption of water treatment will occur at the same time as that of pumping.

NIW has undertaken some work to optimise pumping schedules at a number of sites (those deemed most likely to benefit from flexible operation). Some of these sites operate on an SMP-based tariff, and historical SMP trends have been used to establish pumping schedules. These are not, however, updated to reflect daily variations in the SMP profile. These sites represent the most obvious opportunity for optimisation - updating the day-ahead pumping profile based on the commercially available 24 hour SMP forecast would allow full advantage to be taken of the short-term reductions in SMP from high-wind scenarios.

Most of NIW's sites are on standard time of day tariffs, with DSM limited to avoiding peak tariffs (4pm to $7 \mathrm{pm}$ during November to February) [16].

The focus of this work is a case study of flexible operation on one clean water pumping station in order to investigate the potential economic benefits for the utility. This work is intended as a starting point on an analysis of large scale implementation of water pumping optimisation in support of wind power integration in electricity systems.

There are a number of constraints on water pumping operations - indeed, it is a unit commitment problem in its own right. As such, it cannot be assumed that pumping will only take place during periods of high wind. However, as long as reservoir levels are kept above a minimum level during peak periods, pumping can be maximised off-peak. 
Table 1: NI System and NI Water demand in 2013

\begin{tabular}{|l|r|r|r|r|r|}
\hline Load & Annual & Weekly & Daily & Av. Load & $\%$ \\
\hline NI System (total) $[17]$ & $8750 \mathrm{GWh}$ & $168.3 \mathrm{GWh}$ & $24.04 \mathrm{GWh}$ & $999 \mathrm{MW}$ & $100 \%$ \\
\hline NI Water[16] & $242.21 \mathrm{GWh}$ & $4.65 \mathrm{GWh}$ & $0.664 \mathrm{GWh}$ & $27.65 \mathrm{MW}$ & $2.76 \%$ \\
\hline Clean Water Pumping & $31.04 \mathrm{GWh}$ & $0.6 \mathrm{GWh}$ & $0.085 \mathrm{GWh}$ & $3.5 \mathrm{MW}$ & $0.35 \%$ \\
\hline Clean Water Treatment & $96.02 \mathrm{GWh}$ & $1.85 \mathrm{GWh}$ & $0.26 \mathrm{GWh}$ & $10.96 \mathrm{MW}$ & $1.09 \%$ \\
\hline
\end{tabular}

\section{DSM of Clean Water Pumping}

In this research, models were developed to analyse the implementation of DSM at service reservoirs.

Python models (using the matplotlib library and numpy extension) of the power consumption of the pumping station were created, each of which optimised operation of the pumping station based on a different electricity tariff. Historical SMP [18] data were used for comparison and quantification of the potential savings. The simulation was run on a number of different days' SMP data.

The system modelled was a typical system for the supply of an approximate population of 20,000 people. NIW water supplies 560 million litres of water per day [19], equalling approximate water consumption of 300 1/day/person in NI. This meant that the reservoir must supply in the region of 6 million litres per day. A curve of typical water demand for a given day was input to the model as a series of 96 values, each representing water demand in a 15 minute block. The pumps were modelled as $200 \mathrm{~kW}$ medium head units, capable of pumping $280 \mathrm{l} / \mathrm{s}$. The model optimised PS operation over a 24 hour period. The output information allowed like-for-like comparison of different operating methods. The same simulation was run on versions of the model designed to optimise operation based on different electricity tariffs.

\section{A. Model Inputs and Assumptions}

The model is initialised based on a number of parameters and constraints, all of which can be modified depending on the system being modelled. These are as follows (actual figures used in brackets):

- Water demand over the course of the 24 hour period (96 15-minute blocks)

- Reservoir capacity (8 million litres)

- Reservoir starting level (5 million litres)

- minimum allowable water level in reservoir (4 million litres)

- Pumping rate of the pumps (200,000 litres per 15 minute block)

- Pump power consumption (0.2 MW)

At this point, a number of assumptions are made:

- The pumps are assumed to have binary operation either off or on

- The amount of water in the reservoir is allowed to vary between a specified minimum and maximum value

- The aim of the model is to ensure water is kept between these levels while minimising cost

- Cycling of pumps is not considered as a constraint, nor is the quantity of water available from WTPs
The following equations are true for all models:

$$
\begin{gathered}
R_{i}=R^{\text {start }} \text { for } i=0 \\
R^{\text {min }} \leq R_{i} \leq R^{\text {max }}
\end{gathered}
$$

B. Model Outputs

A run of each model gives the following outputs:

- Graph of reservoir fill level across 24 hour period

- Graph of tariff across 24 hour period

- Graph of SMP across 24 hour period

- Schedule of pump operation across 24 hour period

- Total cost of power

- SMP cost of power consumed

- Average cost per kWh consumed

- Units of power consumed

- Total time of pump operation

- Threshold price (SMP Tariff only)

\section{Tariffs Investigated}

The following tariffs were investigated [20]:

- Business Flatrate - flat cost of $13.65 \mathrm{p} / \mathrm{kWh}$ at all times

- Business Nightsaver 7.99p /kWh (0100h - 0800h), $14.52 \mathrm{p} / \mathrm{kWh}(0800 \mathrm{~h}-0100 \mathrm{~h})$

- Business Multirate (Winter) - 9.14p /kWh (0000 0800), 17.11p /kWh (0800h - 1600h), 23.3p/kWh (1600h - 1900h), 11.58 p/kWh (1900h - 2400h)

- SMP tariff - The SMP for 31 March 2015, in 96 15minute blocks

Each of the tariffs is different in scope and variability; therefore, a different optimisation approach is required for each. The SMP tariff is the primary focus of this investigation, as SMP is affected by wind power penetration, and so day to day mitigation of curtailment would be more likely when load is controlled based on SMP.

Business Flatrate (see equation 3) - This was the simplest of all the models, based on level control. In order to ensure the same reservoir level at the end of the day as at the start, the total pumping requirement for the 24 hour period is divided by the pumping rate of the pumps (per 15 min block). This gives the number of periods during which pumping must occur $(T)$. If the reservoir is not full, the pumps are activated and run until either the reservoir is full or $\sum T_{i}^{\text {run }}=T$. Pumping then stops and the reservoir is allowed to drain. If the fill level reaches the allowed minimum, the pumps activate again and keep pumping until either the reservoir is full or $T$ has been reached.

Business Nightsaver (see equation 4) - This sub-model optimises pumping operation based on a two-tier tariff. 
Pumping is maximised during the off-peak, with the water level being kept as high as possible. During the remaining 17 hours of the day, pumping takes place only to ensure the fill level remains above the minimum.

Business Multirate (Winter) - This model optimises pumping operation based on a four tier tariff. This involves slightly more complex optimisation than the previous sub-models. Pumping is maximised during the first 8 hours of the day as this is the lowest tariff (equation 5). From $0800 \mathrm{~h}$ to $1600 \mathrm{~h}$, the sub-model calculates the total water demand between the current time and 1900 (the end of the highest cost period). If this total is greater than the difference between the current water level and the minimum level, the pumps are activated. This is to ensure that pumping between $1600 \mathrm{~h}$ and $1900 \mathrm{~h}$ is minimised. (equation 6) Pumping from $1600 \mathrm{~h}$ to $2400 \mathrm{~h}$ is kept to an absolute minimum (equation 7 ).

SMP Tariff - (see equation 8) Initially, the model developed was as follows: Total water requirement for the day was calculated. This was then divided by the pump rate (per 15 min block) in order to determine the number of periods during which the pumps would have to operate, and converted to a percentile. This percentile was applied to the SMP data for the given 24 hour period to give a threshold price, $Q$. Below or at this price, the pumps were activated where possible. Above it, pumping was minimised. The threshold price was included in the output. This approach ensured that reservoir level at the end of the period was approximately equal to the starting level.

However, this approach was found to be suboptimal when the SMP data for a given day included large variations or spikes, which would skew $Q$ despite being short in duration. To account for this, the model was further developed to iterate the analysis for a range of values for $Q$ either side of the initially found value. This gives a value for $Q$ closer to the optimum.

\section{Equations}

E. Business Flatrate

$$
R_{i}= \begin{cases}R_{i-1}-D_{i}+P & \text { if } R_{i-1}-D_{i} \leq R^{\text {min }}+P \\ R_{i-1}-D_{i}+P & \text { if } R_{i-1}-D_{i} \leq R^{\max }-P, \quad \sum T_{i}^{\text {run }}<T \text { and } R_{i-1}>R_{i-2} \\ R_{i-1}-D_{i} & \text { if } R_{i-1}-D_{i} \leq R^{\text {max }}-P \text { and } R_{i-1}<R_{i-2} \\ R_{i-1}-D_{i} & \text { otherwise }\end{cases}
$$

F. Business Nightsaver

$$
R_{i}= \begin{cases}R_{i-1}-D_{i}+P & \text { if } R_{i-1}-D_{i} \leq R^{\text {min }}+P \\ R_{i-1}-D_{i}+P & \text { if } R_{i-1}-D_{i} \leq R^{\text {max }}-P \text { and } C_{i}=C^{\text {min }} \\ R_{i-1}-D_{i} & \text { otherwise }\end{cases}
$$

G. Business Multirate

$$
\begin{aligned}
& \text { for } 0 \leq i<32 \text { : } \\
& R_{i}= \begin{cases}R_{i-1}-D_{i}+P & \text { if } R_{i-1}-D_{i} \leq R^{\text {max }}-P \\
R_{i-1}-D_{i} & \text { otherwise }\end{cases} \\
& \text { for } 32 \leq i<64 \text { : } \\
& R_{i}= \begin{cases}R_{i-1}-D_{i}+P & \text { if } R_{i-1}-D_{i} \leq R^{\text {min }}+P \\
R_{i-1}-D_{i}+P & \text { if } R_{i-1}-D_{i} \leq R^{\text {max }}-P \text { and } \sum_{i=i}^{76} D_{i}>R_{i-1}-R^{\text {min }} \\
R_{i-1}-D_{i} & \text { otherwise }\end{cases} \\
& R_{i}= \begin{cases}R_{i-1}-D_{i}+P & \text { if } R_{i-1}-D_{i} \leq R^{\text {min }}+P \\
R_{i-1}-D_{i} & \text { otherwise }\end{cases}
\end{aligned}
$$

H. SMP Tariff

$$
R_{i}= \begin{cases}R_{i-1}-D_{i}+P & \text { if } R_{i-1}-D_{i} \leq R^{\text {min }}+P \\ R_{i-1}-D_{i}+P & \text { if } R_{i-1}-D_{i} \leq R^{\text {max }}-P \text { and } C_{i} \leq Q \\ R_{i-1}-D_{i} & \text { otherwise }\end{cases}
$$




\section{RESULTS}

The figures below are for a model run using SMP data for 31 March 2015.

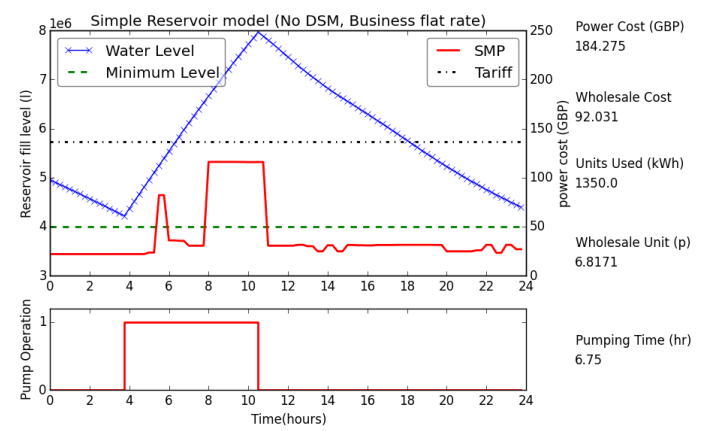

Figure 2: Business Flatrate model run

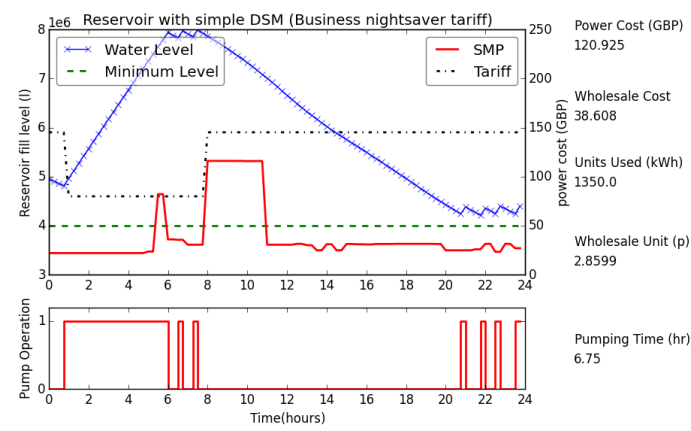

Figure 3: Business Nightsaver model run

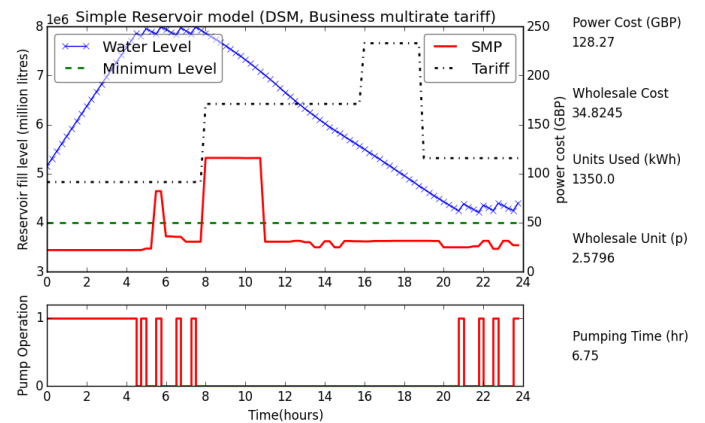

Figure 4: Business Multirate model run

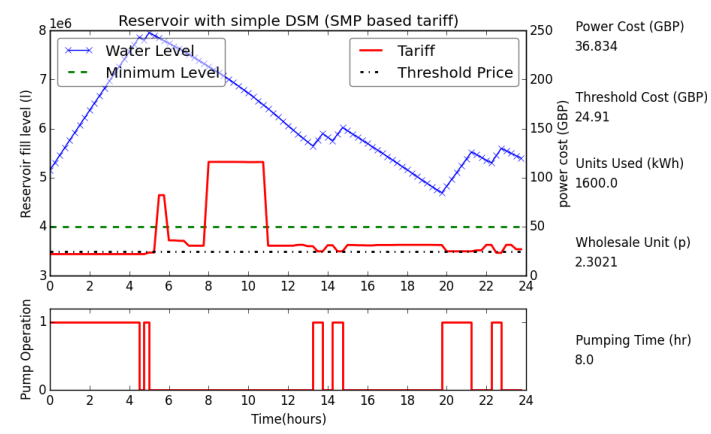

Figure 5: SMP Tariff model run
Table 2: Summary of Results for SMP data from $31 / 03 / 2015$

\begin{tabular}{|l|l|l|l|l|}
\hline Model & $\begin{array}{l}\text { Whole- } \\
\text { sale } \\
\text { Cost }\end{array}$ & $\begin{array}{l}\text { Units } \\
\text { Used }\end{array}$ & $\begin{array}{l}\text { Av. } \\
\text { Unit } \\
\text { cost }\end{array}$ & $\begin{array}{l}\text { Tariff } \\
\text { Cost }\end{array}$ \\
\hline Flatrate & $£ 92.03$ & $1350 \mathrm{kWh}$ & $6.82 \mathrm{p}$ & $£ 184.28$ \\
\hline Nightsaver & $£ 38.61$ & $1350 \mathrm{kWh}$ & $2.86 \mathrm{p}$ & $£ 120.93$ \\
\hline Multirate & $£ 34.82$ & $1350 \mathrm{kWh}$ & $2.58 \mathrm{p}$ & $£ 128.27$ \\
\hline SMP & $£ 36.83$ & $1600 \mathrm{kWh}$ & $2.3 \mathrm{p}$ & $\mathrm{n} / \mathrm{a}$ \\
\hline
\end{tabular}

\section{Discussion}

Table 2 gives a summary of the salient results from one model run with data from 31 March 2015. SMP only takes into account the cost of generation - it does not take into account the cost of transmission, distribution etc [21]. For this reason, and for the purposes of a fair comparison, wholesale (that is to say SMP) cost is only considered here. In reality, any customer on an SMP-based tarriff would pay a surcharge on top of SMP to take into account the true cost of electricity. The wholesale cost in table 2 is the total SMP cost for the periods during which pumping was scheduled.

Although table 2 only shows the data for one day, the pattern was the same across all the days investigated. On average, the wholesale cost per unit for the SMP based schedule was $21 \%, 15.3 \%$, and $15.6 \%$ cheaper than the wholesale costs for the Business Flatrate, Nightsaver and Multirate schedules, respectively.

Even with a $66 \%$ adjustment to the SMP tariff as per [21] (giving an SMP cost for the above table of £61.39) it would still be cheaper than any of the other, more fixed tariffs. The actual savings a customer would experience on an SMP-based tariff would depend on the surcharge to cover non-generation costs mentioned above.

The Multirate tariff investigated was the Winter peak: the same tariff is slightly different outside November to February, with lower peaks costs [20]. With the model used here the results obtained with the normal Multirate tariff were almost identical as pumping was prioritised in the first eight hours of the day, where prices were identical between both tariff bands.

The period of optimisation could have an effect on potential cost savings. Increasing this period from 24 hours to one week would allow daily variations in wind generation and weather patterns to be accommodated more effectively. However, one would have to know the impact that this weather would have on the SMP. Currently, the Irish electricity market provides an SMP forecast one day in advance, which is updated at 0930 on the day itself [22] [23]. Forecasts at longer horizons do not currently exist. This forecast could be used to schedule pumping, but due to the inherent inaccuracy of forecasting would not provide the same level of saving to the water utility as found here. Rolling optimisation (updating the schedule intra-day) would be necessary to benefit from the updating SMP forecast.

The method used here could be further improved by taking into account the availability of water from WTPs and by modelling pumping as variable rather than having binary operation.

This work serves as a starting point for a full inves- 
tigation of the implementation of SMP-based DSM on the full NI Water network and the potential impact on wind generation and system operation. Further work will focus on scaling up the analysis used here and using more advanced optimisation methods.

It should be noted that the approach is applicable to all public water supply systems. Full implementation of the DSM investigated in this research would allow water utilities to make significant savings on electricity costs. From a system operator perspective, it should also increase demand flexibility and thus system stability. Extra renewable generation could then be accommodated, with a corresponding reduction in emissions.

\section{ACKNOWLEDGEMENTs}

The authors would like to thank NI Water for the provision of data.

\section{REFERENCES}

[1] Y. Coughlan et al, "Overcoming operational challenges to maximise the levels of wind integration a system operator perspective", CIGRE, 2012.

[2] L. Soder et al, "Experience and challenges with shortterm balancing in European systems with large share of wind power", IEEE Trans. on Sustainable Energy, vol. 3, no. 4, pp. 853-861, 2012.

[3] E. McKenna, P. Grunewald, and M. Thomson, "Going with the wind: temporal characteristics of potential wind curtailment in Ireland in 2020 and opportunities for demand response", IET Renewable Power Generation, vol. 9, no. 1, pp. 66-77, 2015.

[4] E. V. M. Garrigle, J. P. Deane, and P. G. Leahy, "How much wind energy will be curtailed on the 2020 Irish power system?" Renewable Energy, vol. 55, no. 0, pp. 544-553, 2013.

[5] Poyry, "Wind energy and electricity prices: Exploring the merit order effect", 2010. [Online]. Available: http://www.ewea.org/fileadmin/files/library/ publications/reports/MeritOrder.pdf

[6] A. Keane et al, "Demand side resource operation on the Irish power system with high wind power penetration", Energy Policy, vol. 39, no. 5, pp. 2925-2934, 2011.

[7] A. O'Mahoney and E. Denny, "The merit order effect of wind generation in the Irish electricity market", Department of Economics, Trinity College Dublin,, 2011.

[8] B. Fox et al, "Wind Power Integration: Connection and System Operational Aspects", IET Renewable Energy Series 14, 2014.

[9] M. Klobasa, "Analysis of demand response and wind integration in Germany's electricity market", IET Renewable Power Generation, vol. 4, no. 1, pp. 55-63, 2010 .
[10] T. Gafurov and M. Prodanovic, "Indirect coordination of electricity demand for balancing wind power", IET Renewable Power Generation, vol. 8, no. 8, pp. 858-866, 2014.

[11] B. Smyth, A. Crilly, and K. McDowell, "Water efficiency as a means of reducing carbon emissions in NI Water", Water Efficiency in Buildings Network, 2013. [Online]. Available: http: //www.watefnetwork.co.uk/files/default/resources/ conference_2013/WatefReduceCarbonNI_Smyth.pdf

[12] Derceto, "Washington suburban sanitary commission fact sheet", Derceto, 2012. [Online]. Available: http://www.derceto.com/about-us/pod-files/ Factsheets/120404_9063WSSCfactsheet_web.pdf

[13] S. Thorstensen, "Energy savings analysis generated by a real time energy management system for water distribution", Derceto Ltd, 2007.

[14] M. Wilson and C. Peluso, "Real time water use and energy optimization", CH2M HILL, 2010.

[15] "Irish Water", 2015, May. [Online]. Available: http://www.water.ie/

[16] I. Bingham (NI Water), "Response to enquiry, ref NIW 1415272", December 2014.

[17] SONI, "System Output 2013", 2014. [Online]. Available: http://www.soni.ltd.uk/InformationCentre/ SystemOutput/

[18] Eirgrid, "Smart Grid Dashboard", 2015, May 6. [Online]. Available: http://smartgriddashboard.eirgrid. com/

[19] NI Water, "Annual report and accounts 2013/14", 2014. [Online]. Available: http://www.niwater.com/sitefiles/resources/pdf/ reports/annualreport/niwannualreport2013-14.pdf

[20] A. Stennett, "Power NI: Tariff methodology. research and information service briefing note", NI Assembly, 2013. [Online]. Available: http://www.niassembly.gov.uk/ globalassets/Documents/RaISe/Publications/2014/ enterprise-trade-investment/1214.pdf

[21] Ofgem, "Household energy bills explained", Ofgem, 2013. [Online]. Available: https: //www.ofgem.gov.uk/ofgem-publications/64006/ householdenergybillsexplainedudjuly2013web.pdf

[22] G. Ifrim, B. O'Sullivan, and H. Simonis, "Properties of energy-price forecasts for scheduling", Department of Computer Science, University College Cork, 2012.

[23] SEM-O, "Pricing and scheduling Frequently Asked Questions", 2014. [Online]. Available: http://www.sem-o.com/Publications/General/ Pricing\%20and\%20Scheduling\%20FAQ.pdf 